\title{
Research on viscosity-reduction technology by electric heating and blending light oil in ultra-deep heavy oil wells
}

\author{
Mo Zhu $\cdot$ Haiquan Zhong $\cdot$ Yingchuan $\mathrm{Li} \cdot$ \\ Cheng Zeng $\cdot$ Yue Gao
}

Received: 12 December 2013/ Accepted: 10 June 2014/Published online: 5 July 2014

(C) The Author(s) 2014. This article is published with open access at Springerlink.com

\begin{abstract}
In the Tahe oilfield in China, heavy oil is commonly lifted using the light oil blending technology. However, due to the lack of light oil, the production of heavy oil has been seriously limited. Thus, a new compound technology of light oil blending and electric heating is discussed in this paper, which aims to reduce the usage of light oil and maintain heavy oil production. Based on the mass, momentum and energy conservation, a pressure and temperature coupling model is developed. The heat-transfer parameters are calculated by using Hasan-Kabir method and the pressure drop is calculated by using Hagedorn-Brown method. The model also considers the blend effect of light oil and heavy oil, and the heating effect of electric rod. Example calculation shows that only electric heating or light oil blending technology cannot meet the requirement. The amount of light oil used can be reduced by combining the electric heating technology.
\end{abstract}

Keywords Ultra-deep well · Ultra-heavy oil · Pressure and temperature coupling $\cdot$ Electric heating $\cdot$ Light oil blending

Electronic supplementary material The online version of this article (doi:10.1007/s13202-014-0126-x) contains supplementary material, which is available to authorized users.

M. Zhu $(\bowtie) \cdot$ H. Zhong · Y. Li · C. Zeng

Oil and Gas Reservoir Geology and Exploitation, State Key

Laboratory, Southwest Petroleum University, 610500 Chengdu,

China

e-mail: 71319107@qq.com

Y. Gao

Petro China Southwest Oil and Gas Field Company, Chengdu,

China

\section{Nomenclature}

A Sectional area of the tube, $\mathrm{m}$

$c_{\mathrm{p}} \quad$ Heat capacity, $\mathrm{J} /\left(\mathrm{kg}{ }^{\circ} \mathrm{C}\right)$

$e \quad$ Absolute roughness, $\mathrm{m}$

D Tubing diameter, $\mathrm{m}$

$g_{\text {c }} \quad$ Conversion factor, $3.28 \mathrm{~kg} /\left(\mathrm{N} \mathrm{s}^{2}\right)$

$g \quad$ Gravity constant, $9.81 \mathrm{~m} / \mathrm{s}^{2}$

$g_{\mathrm{G}} \quad$ Geothermal gradient, ${ }^{\circ} \mathrm{C} / \mathrm{m}$

GLR Gas-liquid ratio $\mathrm{m}^{3} / \mathrm{m}^{3}$

$G_{\mathrm{m}} \quad$ Mixture mass flow, $\mathrm{kg} / \mathrm{s}$

$h_{\mathrm{c}} \quad$ Convection heat-transfer coefficient of annular fluid, $\mathrm{W} /\left(\mathrm{m}^{2}{ }^{\circ} \mathrm{C}\right)$

$h_{\mathrm{r}} \quad$ Radiation heat-transfer coefficient of annular fluid, $\mathrm{W} /\left(\mathrm{m}^{2}{ }^{\circ} \mathrm{C}\right)$

$J \quad$ Conversion factor, $184.4 \mathrm{~kJ} / \mathrm{N}$

$k_{\mathrm{c}} \quad$ Coefficient of thermal conductivity of casing, $\mathrm{W} /\left(\mathrm{m}{ }^{\circ} \mathrm{C}\right)$

$k_{\text {cem }}$ Coefficient of thermal conductivity of cement, $\mathrm{W} /\left(\mathrm{m}{ }^{\circ} \mathrm{C}\right)$

$k_{\mathrm{e}} \quad$ Coefficient of thermal conductivity of formation, $\mathrm{W} /\left(\mathrm{m}{ }^{\circ} \mathrm{C}\right)$

$k_{\text {ins }} \quad$ Coefficient of thermal conductivity of insulated tubing coefficient of thermal conductivity, $\mathrm{W} /\left(\mathrm{m}{ }^{\circ} \mathrm{C}\right)$

$k_{\mathrm{t}} \quad$ Coefficient of thermal conductivity of tubing, $\mathrm{W} /\left(\mathrm{m}{ }^{\circ} \mathrm{C}\right)$

$L_{\text {inj }} \quad$ Light oil injection depth, $m$

$q \quad$ Heating power, $\mathrm{W} / \mathrm{m}$

$p_{\text {wh }} \quad$ Wellhead pressure, MPa

$r_{\mathrm{ti}} \quad$ Tubing inside diameter, $\mathrm{m}$

$r_{\text {to }} \quad$ Tubing outside diameter, $\mathrm{m}$

$r_{\mathrm{ci}} \quad$ Casing inside diameter, $\mathrm{m}$

$r_{\mathrm{co}} \quad$ Casing outside diameter, $\mathrm{m}$

$r_{\text {ins }} \quad$ Insulated tubing diameter, $\mathrm{m}$

$r_{\mathrm{wb}} \quad$ Wellbore diameter, $\mathrm{m}$ 
Re Reynolds number, dimensionless

$T_{1}$ (L) Fluid temperature at a depth of $\mathrm{L},{ }^{\circ} \mathrm{C}$

$T_{2}$ (L) Diluting oil temperature at a depth of $\mathrm{L},{ }^{\circ} \mathrm{C}$

$T_{\mathrm{e}}(\mathrm{L})$ Formation temperature, ${ }^{\circ} \mathrm{C}$

$T_{\text {inj }} \quad$ Diluting oil temperature before injection, ${ }^{\circ} \mathrm{C}$

$w \quad$ Mass flow rate, $\mathrm{kg} / \mathrm{hr}$

$W_{1} \quad$ Water equivalent of production fluid $\left(=Q \cdot c_{p} \cdot \rho\right)$, $\mathrm{W} /{ }^{\circ} \mathrm{C}$

$W_{2} \quad$ Water equivalent of light oil, $\mathrm{W} /{ }^{\circ} \mathrm{C}$

$\rho_{\mathrm{m}} \quad$ Mixed fluid density, $\mathrm{m}^{3} / \mathrm{d}$

$\mu_{1} \quad$ Viscosity of light oil, $\mathrm{mPa} \mathrm{s}$

$\mu_{\mathrm{h}} \quad$ Viscosity of heavy oil, $\mathrm{mPa} \mathrm{s}$

$\mu_{\mathrm{m}} \quad$ Viscosity of mixed fluid, $\mathrm{mPa} \mathrm{s}$

$\mu_{\mathrm{i}} \quad$ Viscosity of $i$ fluid, $\mathrm{mPa} \mathrm{s}$

$X_{\mathrm{i}} \quad i$ fluid volume fraction

$\alpha \quad$ Wellbore inclination with horizontal, ${ }^{\circ}$

$\alpha_{1} \quad$ Convection heat-transfer coefficient between fluid and tubing wall, $\mathrm{W} /\left(\mathrm{m}^{2}{ }^{\circ} \mathrm{C}\right)$

$\gamma_{\mathrm{g}} \quad$ Gas gravity (air $\left.=1\right)$, dimensionless

$\rho_{\mathrm{m}} \quad$ Mixture density, $\mathrm{kg} / \mathrm{m}^{3}$

\section{Introduction}

With the continuous decrease of light oil resources, increasingly greater importance is attached to heavy oil resources all around the world. Thanks to the advances in exploration, some ultra-heavy oil reservoirs with deeper depth are gradually developed. Take Tahe oilfield for example, heavy oil characters such as high viscosity $\left(10^{6} \mathrm{mPa} s\right.$ at $\left.50{ }^{\circ} \mathrm{C}\right)$, high wax content (about $\left.40 \%\right)$ and high pour point (about $45^{\circ} \mathrm{C}$ ) cause some problems in production, particularly in winter, where the weather is extremely frigid $\left(<-30{ }^{\circ} \mathrm{C}\right)$. It leads to a sharp increase in oil viscosity and friction pressure gradient in wellbore, which makes it difficult to produce crude oil.

The well depth of Tahe oilfield is about $5,500 \mathrm{~m}$ on average. Steam stimulation, steam drive and SAGD are not applicable, for heat loss in wellbore increases and steam quality decreases sharply (Li et al. 2009). Besides, the disadvantages of water-soluble chemicals are poor effect of viscosity reduction, a large quantity of sewage to deal with and difficulty in water-in-oil emulsion demulsification. Oilsoluble chemicals are flammable, explosive and costly. So, at present, more than $90 \%$ of heavy oil wells in Tahe oilfield produce by diluting. However, more new heavy oil wells have been put into production, which leads to a serious shortage of light oil resources. With the aim of solving this problem, electric heating technology, which is widely applied in China, has been utilized to reduce the usage amount of light oil. So, electric heating-light oil blending compound technology is put forward.
In order to make better use of the electric heating-light oil blending compound technology, a pressure and temperature coupling model, which considers the impact of annular diluting on the radial heat transfer, has been established. Example calculation shows that this compound technology is appropriate for the wells with ultra-high viscosity and depth in harsh environments.

\section{Characteristics of electric heating-light oil blending compound technology}

The wellbore structure is shown as Fig. 1. Light oil is injected through the annular at constant temperature and mixed with the crude oil at the bottom of wells. The electrical heating rod is set down through the tubing and heats the mixed oil. The characteristics of electric heating-light oil blending compound technology is as follows (Li and Zhang 2005):

(1) The construction is simple and special equipment is not needed;

(2) High heating efficiency. The heating source is located in the center of the tubing, so that thermal energy is used to heat the oil around the rod to the greatest extent;

(3) Small energy consumption. Compared with blending light oil through tubing, the friction area is declined by blending light oil through annular.

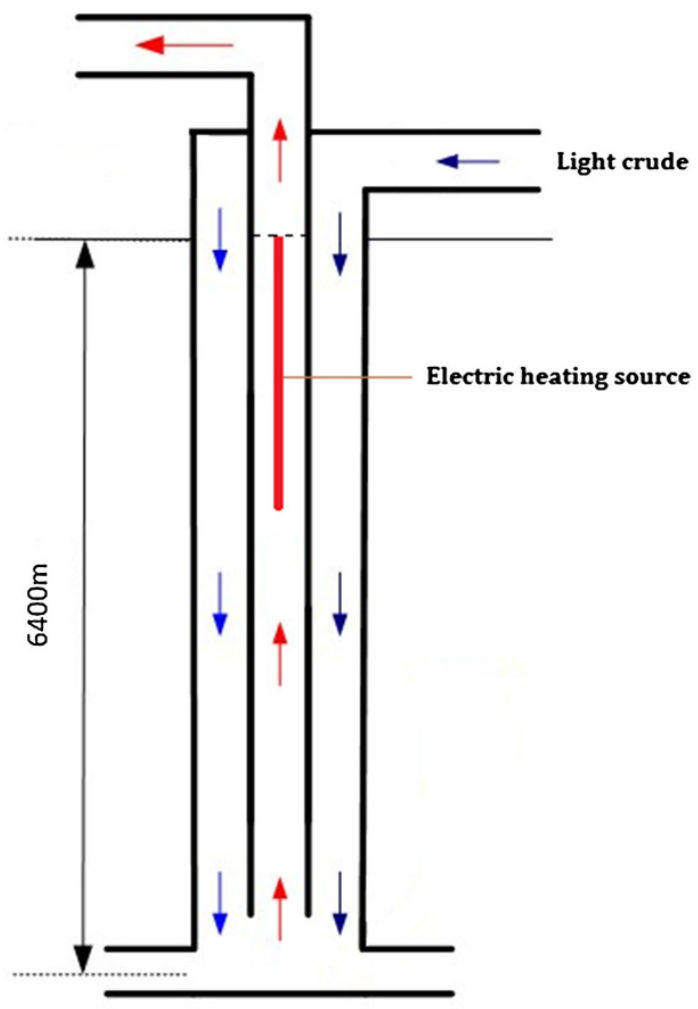

Fig. 1 Wellbore structure of electric heating-light oil blending compound technology 


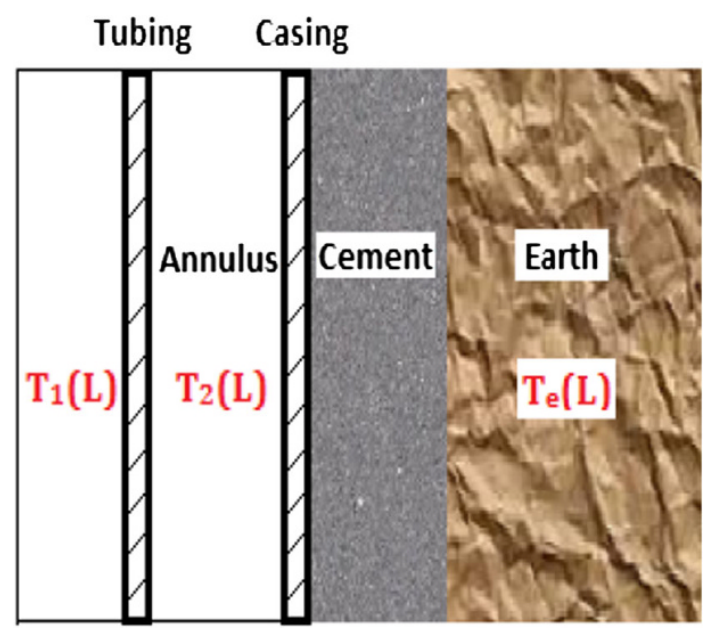

Fig. 2 Heat transfer between the wellbore and formation

(4) Fluid viscosity could be declined and temperature could be increased by the combination of two kinds of technology. Crude oil solidification could be avoided by this kind of technology.

\section{Pressure and temperature coupling model}

Because of the low gas-oil ratio, Hagedorn and Brown (1965) vertical pipe pressure drop calculation method, which has been verified with high accuracy by a number of scholars, is used to calculate the pressure profile. Assuming that the direction of coordinates $\mathrm{Z}$ is consistent with the direction of fluid flow, according to the momentum conservation law, the pressure gradient equation can be expressed as

$\frac{\mathrm{d} p}{\mathrm{~d} l}=-\rho_{\mathrm{m}} g-f_{\mathrm{m}} \frac{G_{\mathrm{m}}^{2}}{2 D A^{2} \rho_{\mathrm{m}}}$

Two phase friction factor $f_{\mathrm{m}}$ calculated using Jain method:

$\frac{1}{\sqrt{f_{\mathrm{m}}}}=1.14-2 \lg \left(\frac{e}{D}+\frac{21.25}{R e^{0.9}}\right)$

Radial heat transfer occurs between the wellbore fluid and the formation. Heat flux flows through tubing wall, tubing insulation, tubing-casing annulus, casing wall and cement. A schematic diagram of heat transfer between wellbore and formation is shown as Fig. 2.

Assuming that degassing and gas expansion energy offsets the energy required by lifting. Electric heating rod is treated as internal heat source ( $\mathrm{Mu}$ and Chen 2000). The heat transfer mathematical model can be expressed as follows (Yan and Li 2012):

$$
\left\{\begin{array}{l}
\frac{\mathrm{d} T_{1}}{\mathrm{~d} l}=\frac{\left(T_{1}-T_{2}\right) K_{1}-q}{W_{1}}+\frac{g \sin \alpha}{c_{\mathrm{p}} J g_{\mathrm{c}}}+\varphi \\
\frac{\mathrm{d} T_{2}}{\mathrm{~d} l}=-\frac{1}{W_{2}}\left[K_{1}\left(T_{2}-T_{1}\right)+K_{2}\left(T_{2}-T_{\mathrm{e}}\right)\right]
\end{array}\right.
$$

Boundary conditions:

$\left\{\begin{array}{l}T_{2}(0)=T_{\text {inj }} \\ T_{1}\left(L_{\text {inj }}\right)=T_{2}\left(L_{\text {inj }}\right)\end{array}\right.$

Equation 3 contains two heat-transfer coefficients $K_{1}$ and $K_{2} . K_{1}$ is defined as the heat-transfer coefficient between the inside and outside of tubing. $K_{2}$ is the heattransfer coefficient between light oil and formation. When heat transfer occurs at steady state, heat flowing through each element must be the same. So, the expressions of the heat-transfer coefficients are as follows (Lin and Li 2006):

$K_{1}=2 \pi\left[\frac{1}{\alpha_{1} r_{\mathrm{ti}}}+\frac{1}{k_{\mathrm{t}}} \ln \left(\frac{r_{\mathrm{to}}}{r_{\mathrm{ti}}}\right)+\frac{1}{k_{\mathrm{ins}}} \ln \left(\frac{r_{\mathrm{ins}}}{r_{\mathrm{to}}}\right)+\frac{1}{\left(h_{\mathrm{c}}+h_{\mathrm{r}}\right) r_{\mathrm{ins}}}\right]^{-1}$

$K_{2}=2 \pi\left[\frac{1}{\left(h_{\mathrm{c}}+h_{\mathrm{r}}\right) r_{\mathrm{ci}}}+\frac{1}{k_{\mathrm{c}}} \ln \left(\frac{r_{\mathrm{co}}}{r_{\mathrm{ci}}}\right)+\frac{1}{k_{\mathrm{cem}}} \ln \left(\frac{r_{\mathrm{wb}}}{r_{\mathrm{co}}}\right)+\frac{f\left(t_{\mathrm{d}}\right)}{k_{\mathrm{e}}}\right]^{-1}$

where dimensionless time $t_{\mathrm{d}}$ can be calculated in the follow equation:

$t_{\mathrm{d}}=\frac{\alpha_{\mathrm{e}} t}{r_{\mathrm{cem}}^{2}}$

where $\alpha_{\mathrm{e}}$ is the thermal diffusivity of formation, $t$ is the heating time. $f\left(t_{\mathrm{d}}\right)$ can be expressed as follows (Hasan and Kabir 2002):

$f\left(t_{\mathrm{d}}\right)=\ln \left[e^{-0.2 t_{\mathrm{d}}}+\left(1.5-0.3719 e^{-t_{\mathrm{d}}}\right) \sqrt{t_{\mathrm{d}}}\right]$

The value of $\varphi$ in Eq. 3 depends on multiple variables, such as flow rate, gas/liquid ratio, and wellbore pressure. Hasan and Kabir (1994) used the following empirical expression for $\varphi$.

$$
\begin{aligned}
\varphi= & -0.007224+6.94 \times 10^{-9} p_{\mathrm{wh}}+8.65 \times 10^{-5} w-1.047 \\
& \times 10^{-6} \mathrm{GLR}+\frac{0.004569}{\rho_{\mathrm{o}}}+0.004009 \gamma_{\mathrm{g}}-0.6472 g_{\mathrm{G}}
\end{aligned}
$$

Equation 3 is a set of differential equations with semiimplicit boundary conditions. The pressure and temperature coupling model is solved as follows (Wen and Li 1998):

(1) The wellbore is divided into $n$ segments. The bottom hole flowing pressure is based on production capacity and assuming that the bottom hole temperature is equal to formation temperature;

(2) Assuming that light oil temperature at the depth of the injection point is $T_{\text {guess }}$, so the blending fluid temperature at the depth of the injection point is $T_{\text {mix }}$;

(3) To inverse the differential Eq. 3, the light oil injection temperature $T_{\text {inj }}$ ' can be calculated;

(4) Compared the $T_{\mathrm{inj}}$ ' with $T_{\mathrm{inj}}$, if the error is less than the design, then output temperature profiles. Otherwise, replace the hypothesis value with the calculation result and repeat $2-4$ process. 
Table $1 Y$ well parameters

\begin{tabular}{llllllll}
\hline Parameters & Symbol & Unit & Value & Parameters & Symbol & Unit & Value \\
\hline Casing size & $d_{\mathrm{c}}$ & $\mathrm{mm}$ & 177.8 & Original formation pressure & $p_{\mathrm{O}}$ & $\mathrm{MPa}$ & 65.02 \\
Tubing size & $d_{\mathrm{t}}$ & $\mathrm{mm}$ & 88.9 & Original formation temperature & $T_{\mathrm{O}}$ & ${ }^{\circ} \mathrm{C}$ & 148 \\
Liquid production & $Q_{\mathrm{L}}$ & $\mathrm{t} / \mathrm{d}$ & $15-50$ & Crude ground density & $\rho_{\mathrm{O}}$ & $\mathrm{g} / \mathrm{cm}^{3}$ & 0.96 \\
Water cut & $f_{\mathrm{w}}$ & $\%$ & 5.3 & Crude volume factor & $B_{\mathrm{O}}$ & $\mathrm{Rm}^{3} / \mathrm{Sm}^{3}$ & 1.15 \\
Original gas-oil ratio & $R_{\mathrm{S}}$ & $\mathrm{m}^{3} / \mathrm{m}^{3}$ & 20 & Formation water density & $\rho_{\mathrm{w}}$ & $\mathrm{g} / \mathrm{cm}^{3}$ & 1.06 \\
\hline
\end{tabular}

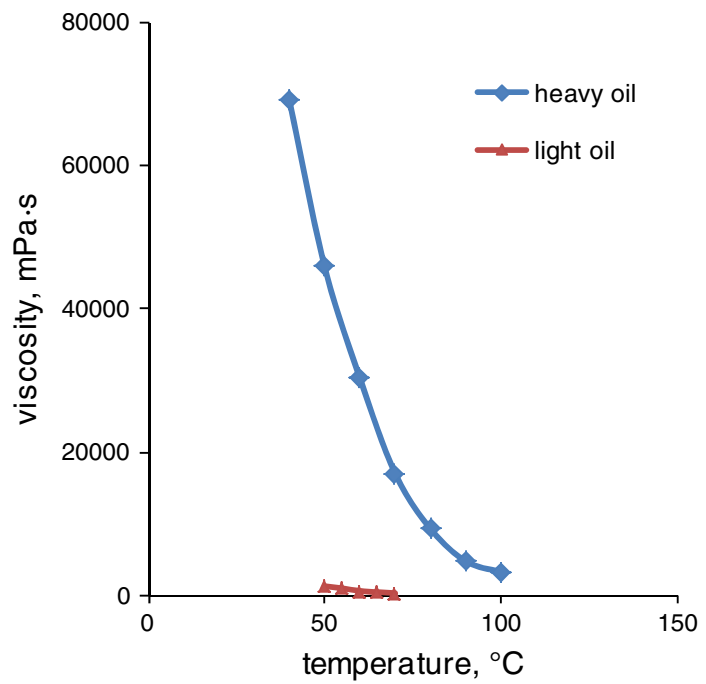

Fig. 3 Viscosity-temperature relationship of heavy oil and light oil

\section{Example calculation and analysis}

Production well data

The depth of $Y$ well is $6,400 \mathrm{~m}$, the formation pressure coefficient is 1.016 , the temperature gradient is $2.03{ }^{\circ} \mathrm{C} /$ $100 \mathrm{~m}$, the reservoir is in the normal temperature and pressure systems. Parameters of $Y$ well are shown in Table 1:

Viscosity-temperature data of crude oil

The measured viscosity-temperature data of crude oil and light oil are shown in Fig. 3.

High pour point oil is viscoplastic non-Newtonian fluid, and the viscosity is extremely sensitive to temperature. When the temperature rises to a certain extent, the viscoplastic fluid will transform into the pseudo-plastic fluid. The transition temperature is defined as the inflection point temperature. According to the viscosity-temperature relationship, the inflection point temperature is $90{ }^{\circ} \mathrm{C}$.

Viscosity-temperature relationship of light oil and heavy oil is fitted as follows:

$\mu_{1}=51973 e^{(-0.074 T)}$

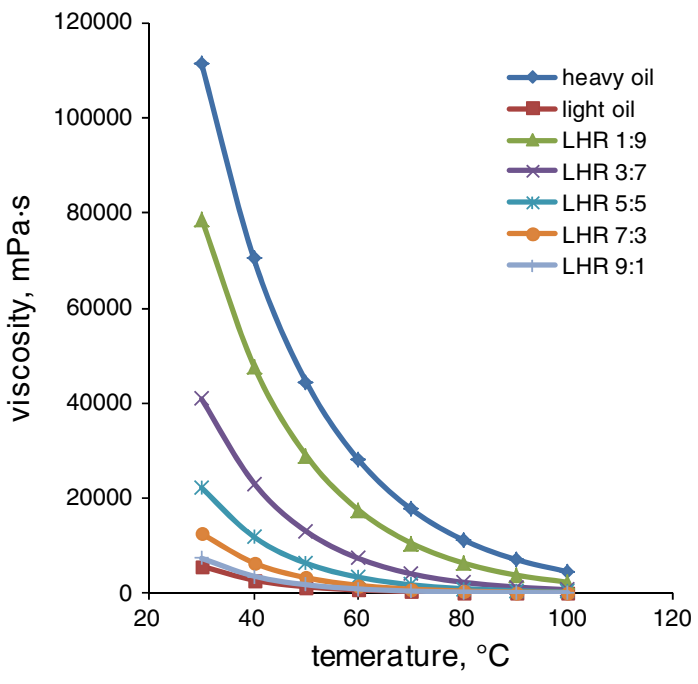

Fig. 4 Viscosity-temperature relationship under different LHR

$\mu_{\mathrm{h}}=443074 e^{(-0.046 T)}$

Cragoe (1933) model has been used to calculate blended fluid viscosity. This model can be used to calculate different proportions of mixed oil. Calculation equation is as follows:

$\left\{\begin{array}{l}\mu_{\mathrm{m}}=5 \times 10^{-4} e^{\left(1000 \ln \frac{20}{L_{\mathrm{m}}}\right)} \\ L_{\mathrm{m}}=\sum_{i=1}^{n} X_{\mathrm{i}} L_{\mathrm{i}} \\ L_{\mathrm{i}}=\frac{1000 \ln 20}{\ln \mu_{\mathrm{i}}-\ln \left(5 \times 10^{-4}\right)}\end{array}\right.$

The viscosity-temperature relationship under different light heavy ratio (the volume ratio of light oil and crude oil, abbreviated to LHR) is shown in Fig. 4.

Parametric analysis

\section{Insulated tubing analysis}

Assuming that liquid rate is $30 \mathrm{t} / \mathrm{d}$, heating power is $50 \mathrm{~W} /$ $\mathrm{m}$ and heating length is $2,000 \mathrm{~m}$, the thermal conductivity of insulating tubing is $0.05 \mathrm{~W} /\left(\mathrm{m}^{\circ} \mathrm{C}\right)$. Crude oil production is not mixed with light oil. Based on the above 


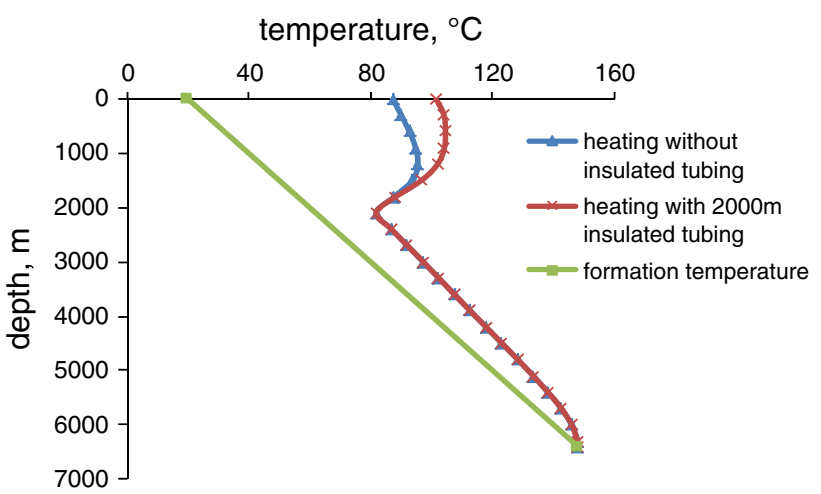

Fig. 5 Influence of insulated tubing to crude temperature

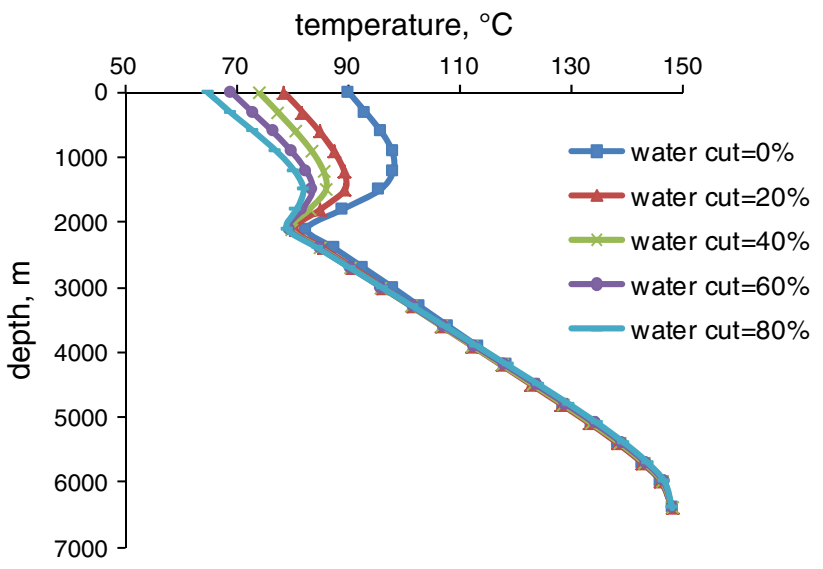

Fig. 6 Influence of different water cut to crude temperature

conditions, the calculation results are shown in Fig. 5. After using the insulated tubing, wellbore temperature increased significantly from 87.2 to $101.5^{\circ} \mathrm{C}$.

\section{Water cut analysis}

When water cut increases, the effect of electrical heating will decrease. That is because the enthalpy of water is higher than oil. To change $1{ }^{\circ} \mathrm{C}$ requires more heat. In addition, high water cut leads to the emulsification of heavy oil, which can result in higher fluid viscosity (Fig. 6).

\section{Heating section analysis}

Assuming that heating power is $50 \mathrm{~W} / \mathrm{m}$ and heating length is $1,600 \mathrm{~m}$. The temperature distribution under different heating sections is calculated and the calculation results are shown in Fig. 7. When the heating length is a constant, the heating start point has significant effect on heating, the deeper the heating start point is, the more heating energy loss for the larger difference in temperature between fluid and formation after heating. Therefore, heating from the wellhead can maximize the use of heat energy.

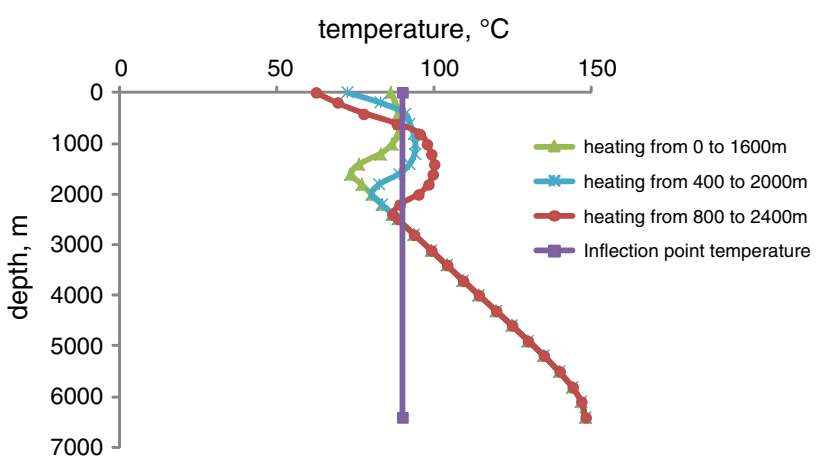

Fig. 7 Temperature distribution with different initial heating position

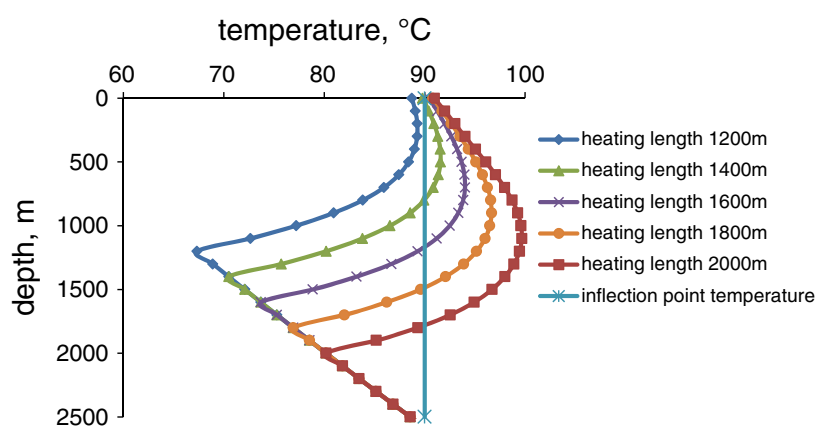

Fig. 8 Influence of different heating length to crude temperature

\section{Heating length analysis}

Assuming that liquid rate is $30 \mathrm{t} / \mathrm{d}$ and heating power is $60 \mathrm{~W} / \mathrm{m}$, heavy oil production is not mixed with light oil, the temperature distribution under different heating lengths is calculated. The calculation results are shown in Fig. 8 (this is a partial view of wellbore temperature distribution). With the heating length increasing, heavy oil is heated from a deeper depth and oil temperature is increased to inflection temperature earlier. However, temperature increasing almost remains the same at wellhead for heavy heat loss caused by the formation.

\section{Heating power analysis}

Assuming that heating length is $2,000 \mathrm{~m}$ and other conditions remain the same, temperature distribution under different heating power is calculated. The results are shown in Fig. 9 (this is a partial view of wellbore temperature distribution). The heating sections temperature is quite different with the change of heating power. The higher heating power is, the better heating effect is.

From what has been analyzed above, the length of wellbore section, whose temperature above the inflection point temperature, was determined by the heating length and the heating power. The heating length determined the 


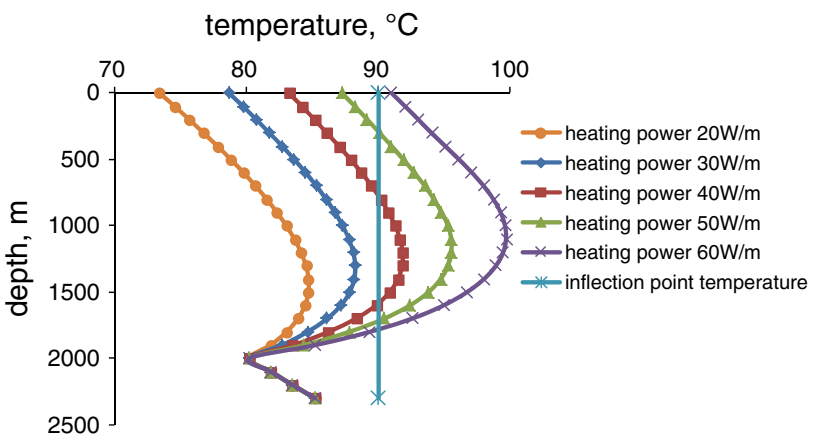

Fig. 9 Influence of different heating power to crude temperature

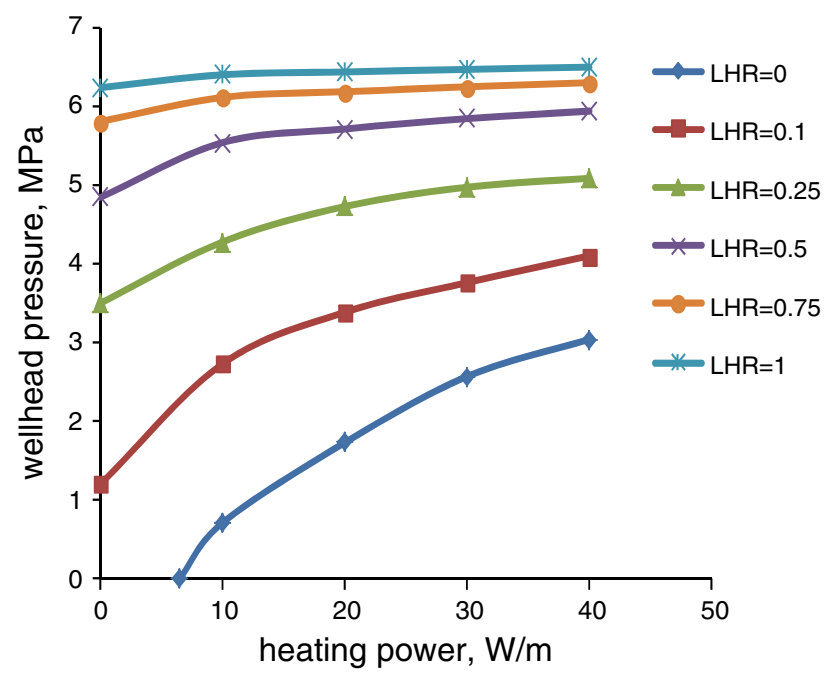

Fig. 10 Wellhead pressure-heating power in different LHR

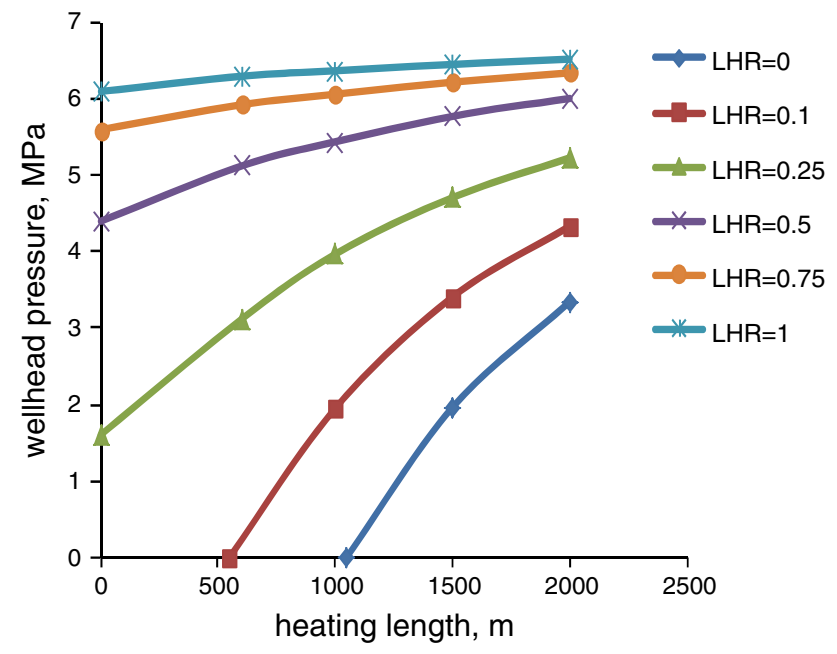

Fig. 11 Wellhead pressure-heating length in different LHR

start point of heating; the heating power determined how long the wellbore temperature remained above the inflection point temperature.

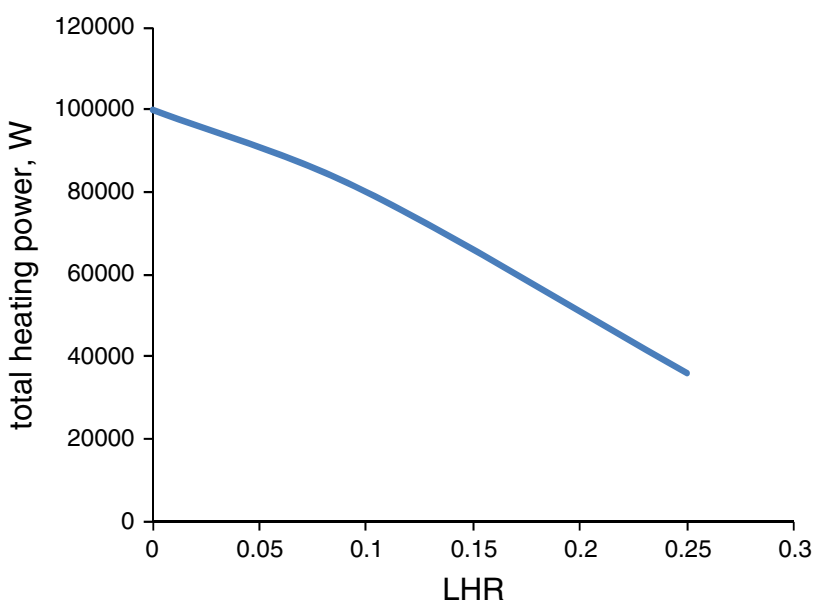

Fig. 12 Relationship between total heating power and LHR

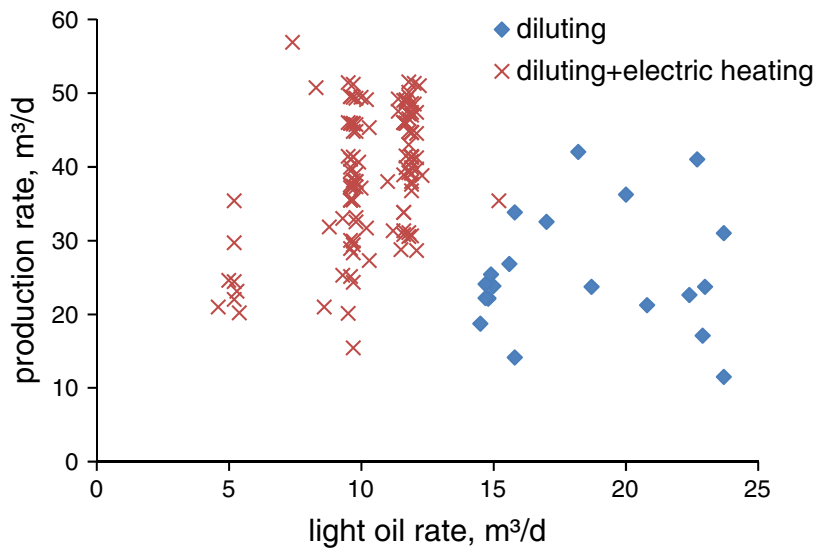

Fig. 13 The relationship between light oil rate and production rate of $Y$ well

At present, the limit depth of electric heating rod is about 2,000 m. However, heating length of 2,000 $\mathrm{m}$ is not able to meet the requirement that crude oil temperature is higher than the inflection point temperature. For ultraheavy oil, electric heating cannot replace blending light oil, but can reduce the amount of light oil and avoid crude oil solidification.

As shown in Figs. 10 and 11, when heating power or heating length is fixed, if LHR increases, the wellhead pressure will increase. When LHR is fixed, increasing heating length and power also can increase wellhead pressure. When LHR is more than 0.5, as the amount of light oil increases, the variation of wellhead pressure becomes not obvious. That is because the viscosity of heavy oil has been reduced significantly by heating. So, in the condition of low LHR, it could reduce the amount of light oil by increasing heating length and power. The relationship of LHR and the total heating power is shown in Fig. 12. 


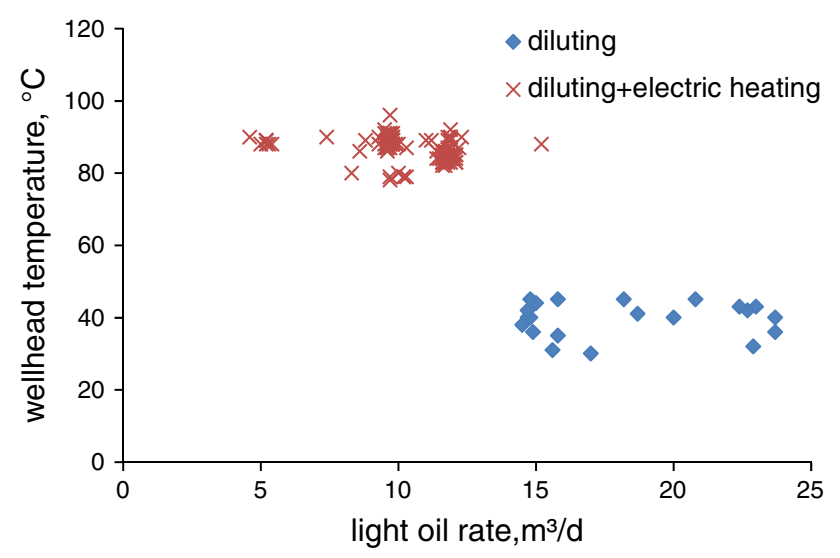

Fig. 14 The relationship between wellhead temperature and light oil rate of $Y$ well

\section{Field application}

$Y$ well produced by diluting in the early production, while electric heating technology has been utilized for the shortage of light oil resources. According to the production history, the relationship between light oil rate and production rate under the condition of 2,000 m heating length and $50 \mathrm{~W} / \mathrm{m}$ heating power is shown in Fig. 13. The relationship between wellhead temperature and light oil rate is shown in Fig. 14.

After electric heating, the average oil production increased $13.7 \mathrm{t} / \mathrm{d}$ and the average light oil consumption decreased from 17.8-9.6 t/d and was $54 \%$ of earlier consumption. What's more, the temperature of produced fluid increased significantly and wellhead temperature increased about $40{ }^{\circ} \mathrm{C}$.

The field test results showed that application of electric heating-light oil blending compound technology in heavy oil producing can significantly decrease the consumption of light oil. Meanwhile, wax deposition and solidification could be avoided.

\section{Conclusions}

(1) Based on the wellbore flow characteristics of heavy oil produced by electric heating and light oil blending, the coupling model about pressure and temperature distribution has been established. And the numerical solution is given.
(2) Insulated tubing can effectively reduce the heat loss of wellbore. The better the insulated tubing is, the less the heating energy loses. With water cut increasing, the capacity of produced fluid increases, which will reduce the effect of electric heating.

(3) Increasing heating length can improve fluid temperature from deeper depth, but has little effect on wellhead temperature. Wellhead temperature can be improved by increasing the heating power.

(4) The wellbore fluid cannot be heated up to the inflection temperature by single use of electric heating technology for electric rod cannot reach to the depth deep enough, either do diluting technology for the shortage of light oil. Therefore, the electric heating and light oil blending compound technology can be employed in ultra-heavy wells. Under the condition of low LHR, the viscosity of crude oil can be reduced and the wellhead pressure can be increased by increasing heating length and power.

Open Access This article is distributed under the terms of the Creative Commons Attribution License which permits any use, distribution, and reproduction in any medium, provided the original author(s) and the source are credited.

\section{References}

Hagedorn AR, Brown KE (1965) Experimental study of pressure gradients occurring during continuous two-phase flow in small diameter vertical conduits. SPE Petroleum Technol pp 475-484

Hasan AR and Kabir (1994) Aspects of wellbore heat transfer during two-phase flow. SPE Prod Facil pp 211-216

Hasan AR and Kabir (2002) Fluid flow and heat transfer in wellbores. Soc Pet Eng Richardson pp 64-69

Li YC et al (2009) Petroleum production engineering. Beijing Pet Ind Press, pp 333-335 (in Chinese)

Li SB, Zhang ZH (2005) Wellbore electrical heating technology application in heavy oil recovery. Oil Gasfield Surface Engineering 24:29-30

Lin RY, Li ZM (2006) Technology of blending diluting oil in ultradeep wellbore of Tah oilfield. ACtA Petrolei Sinica 30:67-70

Mu JB, Chen H (2000) Application of electric-heating oil producing technology in Gudao oil field (natural science edition). J Xi' Pet Inst 15:19-21

Wen SP, Li XC (1998) Numerical solution of equation for hot fluid circulation. J Univ Pet 3:264-270

Yan YJ, Li YS (2012) Diluting oil blending technology research and application in Tah oilfield. Pet Geol Eng 26:108-110 